\title{
Phenotypic and genetic relationships between age at first calving, its component traits, and survival of heifers up to second calving
}

\author{
Johannes Heise ${ }^{* 1}$ Kathrin F. Stock, $\nmid$ Friedrich Reinhardt, $\uparrow$ Ngoc-Thuy Ha, ${ }^{*}$ and Henner Simianer* \\ *University of Goettingen, Animal Breeding and Genetics, 37075 Göttingen, Germany \\ †IT Solutions for Animal Production (VIT), Heinrich-Schröder-Weg 1, 27283 Verden, Germany
}

\begin{abstract}
The aim of this study was to answer the question whether models for genetic evaluations of longevity should include a correction for age at first calving (AFC). For this purpose, phenotypic and genetic relationships between AFC, its component traits age at first insemination (AFI) and interval from first to last insemination (FLI), and survival of different periods of the first lactation (S1: 0 to 49 d, S2: 50 to 249 d, S3: $250 \mathrm{~d}$ to second calving) were investigated. Data of 721,919 German Holstein heifers, being inseminated for the first time during the years from 2003 to 2012, were used for the analyses. Phenotypic correlations of AFI, FLI, and AFC to S1 to S3 were negative. Mean estimated heritabilities were 0.239 (AFI), 0.007 (FLI), and 0.103 (AFC) and 0.023 (S1), 0.016 (S2), and 0.028 (S3) on the observed scale. The genetic correlation between AFI and FLI was close to zero. Genetic correlations between AFI and the survival traits were -0.08 (S1), -0.02 (S2), and -0.10 (S3); those between FLI and the survival traits were $-0.14(\mathrm{~S} 1),-0.20(\mathrm{~S} 2)$, and -0.44 (S3); and those between AFC and the survival traits were -0.09 (S1), -0.06 (S2), and -0.20 (S3). Some of these genetic correlations were different from zero, which suggests that correcting for AFC in genetic evaluations for longevity in dairy cows might remove functional genetic variance and should be reconsidered. Key words: age at first calving, survival, longevity, age at first insemination
\end{abstract}

\section{INTRODUCTION}

Longevity is an economically important (Allaire and Gibson, 1992) and publicly discussed trait in dairy cows. Routine genetic evaluations for this trait are conducted in all major dairy breeding countries (Miglior

Received March 30, 2017.

Accepted September 19, 2017.

${ }^{1}$ Corresponding author: johannes.heise@uni-goettingen.de et al., 2005; Interbull, 2016). After years of routine genetic evaluations for longevity, some recent studies have reviewed this trait complex (Sasaki et al., 2015; van Pelt et al., 2015; Heise et al., 2016). In research studies (Ducrocq, 2005; Sewalem et al., 2007; Sasaki et al., 2015; van Pelt et al., 2015) as well as routine genetic evaluations in many countries (Interbull, 2016), longevity is corrected for age at first calving (AFC), either in the form of a covariate (Sewalem et al., 2007) or as a fixed class effect (Ducrocq, 2005). In the following countries, which participate in Interbull genetic evaluations, longevity is corrected for AFC in either form: Canada, Czech Republic, Denmark-FinlandSweden, France, Germany, Great Britain, Hungary, Ireland, Israel, Italy, Netherlands, Poland, Republic of South Africa, Slovenia, Spain, and Switzerland. In Australia, Belgium, New Zealand, and the United States, longevity is not corrected for AFC (Interbull, 2016). In genetic evaluations, this is only justifiable if AFC predominantly reflects environmental factors with no genetic correlation to longevity. There are reasons to reconsider this hypothesis: AFC can be dissected into age at first insemination (AFI), time from first to last (or successful) insemination (FLI), and gestation length. All these traits are functional traits and were shown to be heritable in previous studies (AFI: Mäntysaari et al., 2002; Jamrozik et al., 2005; FLI: Berry et al., 2003; Liu et al., 2008; gestation length: Jamrozik et al., 2005; Norman et al., 2009). Especially, FLI is a widely used reproduction trait and part of the total merit index in various countries, including Germany (Interbull, 2016). Phenotypically, impaired reproductive performance increases the risk of culling (Rajala-Schultz and Gröhn, 1999), and positive genetic correlations between more favorable expressions of reproduction traits and survival were also reported (Campos et al., 1994; HaileMariam et al., 2003). Despite the mentioned results, literature on genetic relationships between AFC or AFI and survival is scarce. Furthermore, most previous studies on genetic relationships between survival and other traits considered survival of relatively long periods; for example, survival of the complete first 
lactation (Visscher and Goddard, 1995; Dematawewa and Berger, 1998; Haile-Mariam et al., 2003). Recent studies (Sasaki et al., 2015; van Pelt et al., 2015; Heise et al., 2016) suggest that the genetic background for survival of different periods within the same lactation is not the same. The aim of this study was to investigate the genetic relationships between AFC, its underlying traits, and survival of different periods of the first lactation. Knowledge about these relationships is crucial for appropriate modeling of longevity in routine genetic evaluations.

\section{MATERIALS AND METHODS}

\section{Data}

The data used in this study originate from national routine genetic evaluations for Holstein cattle in Germany (VIT, 2016) and were selected by applying the selection steps described in Table 1. The traits AFI and FLI were restricted to plausible ranges: 330 to $800 \mathrm{~d}$ for AFI and 0 to $210 \mathrm{~d}$ for FLI. Additionally, the interval from last insemination to first calving was required to be within the range from 265 to 295 d. The last step included sampling of herds within 5 federal states in Germany such that at least 100,000 records were in each data set. This procedure resulted in 5 sample data sets consisting of in total 721,919 cows $(111,388$ to 174,102 each) from 10,643 sires.

\section{Trait Definitions}

The individual records for AFI, FLI, and AFC were derived from the available data of the sampled animals. Following Heise et al. (2016), 3 survival traits within the first lactation were defined as follows: the first par- ity was divided in the periods 0 to $49 \mathrm{~d}$ (S1), 50 to 249 $\mathrm{d}$ (S2), and $250 \mathrm{~d}$ from calving until the second calving (S3). If a cow survived until the end of a period, given that she had survived all previous periods, her observation for survival was coded "1"; if she was culled in the period of consideration, her observation for survival was coded " 0 "; and if the cow was sold or culled in one of the previous periods, her observation record of survival for the regarded period was considered missing.

\section{Phenotypic Analyses}

Survival rates and risk of culling for S1 to S3 were estimated following Kaplan and Meier (1958) with the survfit() function from the survival package (Therneau, 2016) in R (R Core Team, 2016).

To evaluate phenotypic relationships between AFI, FLI, and AFC and the survival traits S1 to S3, the traits AFI, FLI, and AFC were coded as discrete variables (monthly steps for AFI and AFC, ranging from 12 to $21 \mathrm{mo}$ and from 21 to $32 \mathrm{mo}$, respectively; 21-d steps for FLI, ranging from 0 to $147 \mathrm{~d}$ ). Univariate logit threshold models were fitted as

$$
\mathbf{y}^{*}=\mathbf{X b},
$$

where $\mathbf{y}^{*}$ is a latent variable that is linked to $\mathbf{y}$ via a logit-function; $\mathbf{y}$ is a vector comprising survival observations $(1 / 0)$ for $\mathrm{S} 1, \mathrm{~S} 2$, or $\mathrm{S} 3 ; \mathbf{X}$ is an incidence matrix linking observations to classes of fixed effects; and $\mathbf{b}$ is a vector of fixed effects (AFI, FLI, or AFC). This resulted in 9 models with survival traits as dependent variables and AFI, FLI, and AFC as independent variables. The analysis was conducted using the function $\operatorname{glm}()$ from the $\mathrm{R}$ package stats (R Core Team, 2016).

Table 1. Data selection steps and criteria

\begin{tabular}{ll}
\hline Step: Selection of & Criterion \\
\hline (1) Insemination bulls & (a) Holsteins only \\
& (b) Semen used in at least 10 herds \\
(2) Insemination records & (a) Bulls from step 1 \\
& (b) Conventional (non-sexed) frozen semen only \\
(3) Cows & (a) Holsteins only \\
& (b) Both parents known \\
& (c) Stayed in the same herd until first calving \\
& (d) All inseminations on the cow passed step 2 \\
& (e) Known record of first calving \\
& (f) Record of first insemination within the years 2003 to 2012 \\
(4) Herds & (a) At least 20 first inseminations (from step 3) on heifers per year from 2003 to 2015 \\
(5) Sires & (b) Sampling of herds within 5 of the German federal states \\
\hline
\end{tabular}


Table 2. Descriptive statistics for the traits age at first insemination (AFI), interval from first to last insemination (FLI), and age at first calving (AFC) as well as for the interval from last insemination to calving (all samples)

\begin{tabular}{lcccc}
\hline Description & Mean & Median & Minimum & Maximum \\
\hline AFI (mo) & 16.23 & 15.87 & 10.84 & 26.29 \\
FLI (d) & 17.94 & 0 & 0 & 210 \\
Last insemination to first calving (d) & 278.52 & 279 & 265 & 295 \\
AFC (mo) & 25.97 & 25.57 & 19.65 & 41.34 \\
\hline
\end{tabular}

\section{Genetic Analyses}

Genetic parameters were estimated from the following linear multiple trait sire model:

$$
\mathbf{y}=\mathbf{X b}+\mathbf{Z s}+\mathbf{e}
$$

where $\mathbf{y}$ is a vector of observations; $\mathbf{X}$ is an incidence matrix linking the observations to the fixed effects; $\mathbf{b}$ is the vector of fixed effects; that is, herd $x$ year $x$ season at first insemination; $\mathbf{Z}$ is the incidence matrix of the random sire effects; $\mathbf{s}$ is the vector of random sire effects $\left[\mathbf{s} \sim N\left(0, \mathbf{G}_{\mathrm{s}} \otimes \mathbf{A}\right)\right]$, with the covariance matrix of sire effects $\mathbf{G}_{\mathrm{s}}$ and the numerator relationship matrix for sires $\mathbf{A}$; and $\mathbf{e}$ is a vector of random residual effects $\left[\mathbf{e} \sim N\left(0, \mathbf{R}_{\mathrm{s}} \otimes \mathbf{I}\right)\right]$, with the residual covariance matrix $\mathbf{R}_{\mathrm{s}}$, including the variances of dams' genetic effects and Mendelian sampling. The genetic covariance matrix for animals, $\mathbf{G}_{0}$, was then estimated as $4 \mathbf{G}_{\mathrm{s}}$ and the respective residual covariance matrix $\mathbf{R}_{0}$ as $\mathbf{R}_{\mathrm{s}}-3 \mathbf{G}_{\mathrm{s}}$.

Variance components were estimated for different trait combinations using the above model and the software package VCE (Groeneveld et al., 2010). Two trait combinations were run: (1) including S1 to S3, $\mathrm{AFI}$, and FLI; and (2) including S1 to S3 and AFC. Because of the dependency of AFC on AFI and FLI, models including these 3 traits simultaneously did not converge. Joint results from the different samples for genetic parameter estimates are presented as means with standard deviations.

Table 3. Kaplan-Meier estimators for the risk of culling, conditional on survival of the previous periods, and respective survival rates with standard errors

\begin{tabular}{lccc}
\hline & & \multicolumn{2}{c}{ Survival } \\
\cline { 3 - 4 } Trait $^{1}$ & $\begin{array}{r}\text { Risk of } \\
\text { culling }\end{array}$ & Rate & SE \\
\hline S1 & 0.073 & 0.927 & 0.0003 \\
S2 & 0.078 & 0.855 & 0.0004 \\
S3 & 0.103 & 0.766 & 0.0005 \\
\hline
\end{tabular}

${ }^{1} \mathrm{~S} 1$ to $\mathrm{S} 3=$ survival of the periods 0 to $49 \mathrm{~d}, 50$ to $249 \mathrm{~d}$, and $250 \mathrm{~d}$ to the second calving, respectively.

\section{RESULTS}

\section{Phenotypic Relationships Between AFI, FLI, AFC, and Survival}

Descriptive statistics of AFI, FLI, and AFC are given in Table 2. Means over all samples for AFI, FLI, and AFC were $16.23 \mathrm{mo}, 17.94 \mathrm{~d}$, and $25.96 \mathrm{mo}$, respectively. Kaplan-Meier estimators for risk of culling and survival rates can be seen in Table 3. Proportions of 93, 86, and $77 \%$ of cows with a reported first calving survived until the end of periods S1, S2, and S3, respectively.

Predicted survival probabilities from the logit threshold model for S1 to S3, dependent on either AFI, FLI, or AFC as fixed effect, can be seen in Figure 1. The probabilities for S2 and S3 are conditional on survival of the preceding periods. Predicted survival probabilities for S3, affected by AFI, declined from 0.91 (12 mo) to 0.86 ( $\geq 21 \mathrm{mo}$ ), from 0.90 ( 0 to $20 \mathrm{~d}$ ) to 0.85 ( $\geq 147$ d) for the effect of FLI, and from $0.91(22 \mathrm{mo})$ to 0.84 $(\geq 32 \mathrm{mo})$ for AFC. Effects of AFI, FLI, and AFC on $\mathrm{S} 1$ and $\mathrm{S} 2$ showed the same trend; that is, cows with longer intervals had reduced survival probabilities.

\section{Genetic Parameters}

Estimated genetic and residual relationships between AFI, FLI, and AFC and the 3 survival traits are given in Table 4. For AFI, a mean heritability of 0.24 was estimated. Genetic correlations to the survival traits S1 and S3 were slightly negative $(-0.08$ and -0.10$)$ and close to zero for S2. For FLI, a mean heritability of 0.007 was estimated. Genetic correlations between FLI and S1 $(-0.14)$ and S2 $(-0.20)$ were weaker than those between FLI and S3 (-0.44). The mean heritability estimate for AFC was 0.10. Mean genetic correlations to survival traits were $-0.09(\mathrm{~S} 1),-0.06(\mathrm{~S} 2)$, and -0.20 (S3).

\section{DISCUSSION}

\section{Data}

For this study, relatively large herds were chosen compared with the average German herd size. This 
choice had 3 advantages: first, cows in bigger herds can be expected to be all treated in a similar way, with as few preferential treatments as possible. Second, the rel-
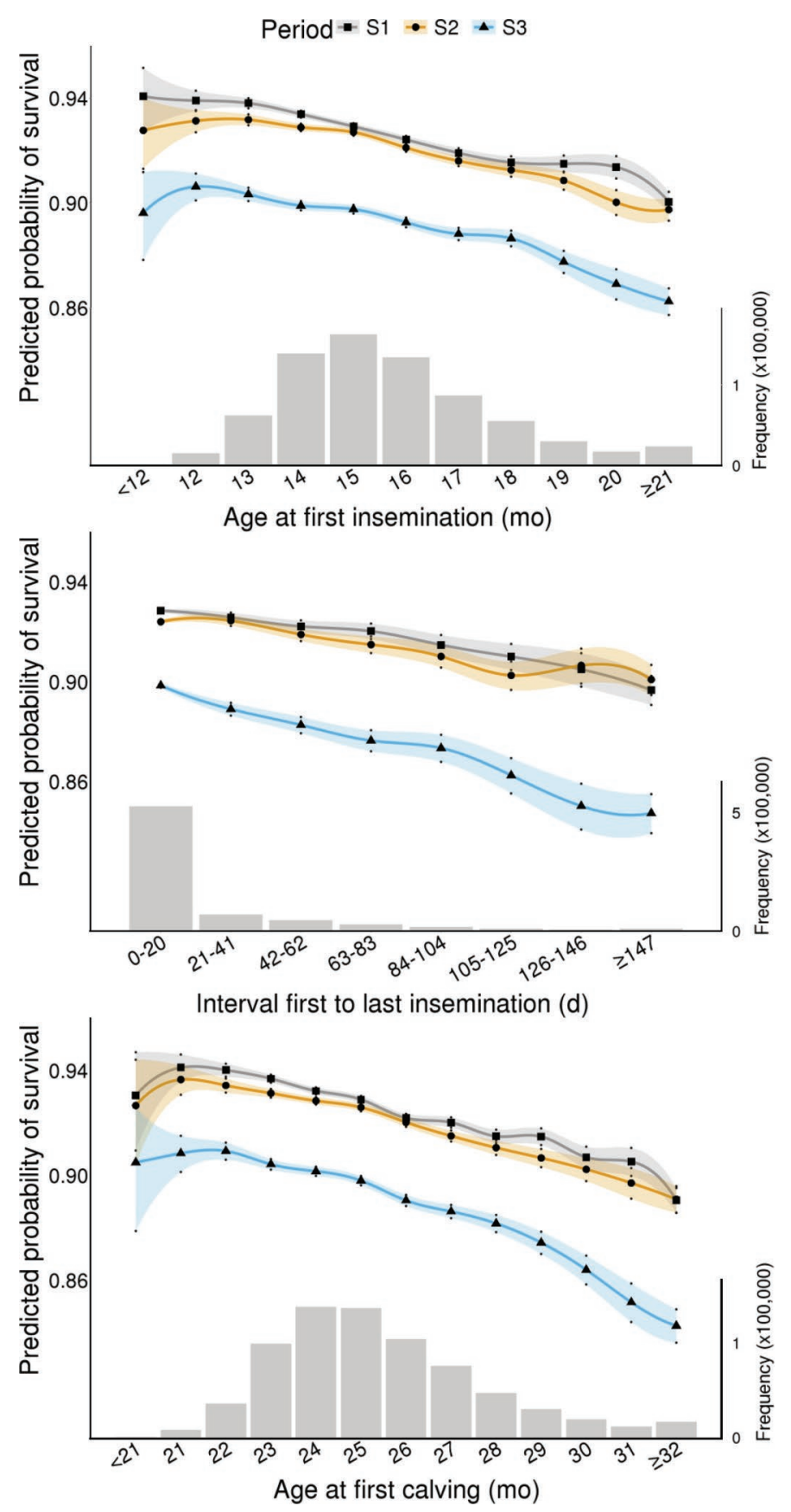

Figure 1. Predicted probabilities for survival (left y-axis) of different periods of the first lactation (S1 to S3; 0 to 49 d, 50 to 249 d and $250 \mathrm{~d}$ to the second calving, respectively) from a logit model, dependent on age at first insemination, interval from first to last insemination, and age at first calving as fixed effects. Ribbons indicate pointwise $95 \%$ confidence intervals. Gray bars (right y-axis) represent absolute frequencies for the respective classes. Color version available online. atively large herds used in our analysis allowed for the inclusion of a fixed herd $\times$ year $\times$ season-effect. This is favorable, because a pre-analysis showed a seasonal pattern for all traits. And third, herd sizes in Germany are increasing (Destatis, 2013), so our results can be considered a reliable basis for future decisions concerning genetic evaluations of the studied trait complex.

\section{Model Choice}

Although survival traits were considered as binary traits and the other variables (AFI, FLI, and AFC) were non-normally distributed, a linear sire model was chosen for estimation of variance components. We made this choice mainly because the new routine genetic evaluation for longevity of Holsteins in Germany will likely be based on a linear model, including the survival traits of the first lactation as considered here. The primary motivation of the current study was to investigate the relationship of $\mathrm{AFC}$ and $\mathrm{S} 1$ to $\mathrm{S} 3$ for this scenario. The choice of a linear model for the development of a new routine genetic evaluation of longevity was mainly due to the heavily increased computation time for survival and threshold models compared with linear models. Boettcher et al. (1999) reported this increase to be by a factor of 5 to 10 , which would not be feasible for a multiple-trait animal model in the German national genetic evaluation system. Furthermore, other studies revealed good performance of linear models for genetic evaluations of binary survival traits (Boettcher et al., 1999; Holtsmark et al., 2009). The choice of a linear model for binary variables influences the scale of $\mathrm{h}^{2}$ (Dempster and Lerner, 1950) but does not have a scale effect on estimates of genetic correlations (Vinson et al., 1976; Gianola, 1982). With regard to the estimation of variance components of the other non-normally distributed variables (AFI, FLI, and AFC), Raheja et al. (1989) found no benefit from transforming AFI, age at last insemination, or number of inseminations to approximate normal distributions.

\section{Phenotypic Relationships}

The sum of AFI and FLI explained 99.6\% of the variance of AFC. This implies that gestation length only explains a minor proportion of the variance of AFC, which is in good accordance with results of Jamrozik et al. (2005).

With regard to the survival traits, Kaplan-Meier estimates of proportions of cows that survived the defined segments of the first lactation were similar to those of a previous study (Heise et al., 2016) in a similar data set.

The onset of puberty is known to be much more strongly influenced by BW development than by age 
(as reviewed by Sejrsen and Purup, 1997), suggesting that AFI primarily reflects the growth development of heifers. Slow-growing heifers were reported to have a lower probability of survival up to the second lactation than faster-growing heifers (Bach, 2011), which is in accordance with our results.

The effect of FLI was somewhat stronger on S3 than on S1 and S2. This is in accordance with studies on reasons for disposal, which indicated that culling for infertility or reproduction-related causes occurs mainly toward the end of the lactation (Pinedo et al., 2010; Heise et al., 2016). The effect of AFC was also somewhat stronger on S3 than on S1 and S2. Among the cows being culled before the second calving, the probability of being culled for "infertility" increased from 0.19 to 0.22 when the interval FLI increased from the " 0 to 20 d" class to the " $\geq 147$ d" class. This supports that a cow that had difficulty becoming pregnant as a heifer has a slightly increased risk to be culled for reproduction problems during the first lactation. These results are in accordance with Bach (2011), who found that cows needing more than 1 service to conceive as a heifer had a reduced probability to finish the first lactation. For example, the probability to finish first lactation for cows needing 2 services to conceive as a heifer was 0.74 times the probability of cows needing only 1 service.

The effect of AFC on survival traits was in general agreement with the literature (Gill and Allaire, 1976; Nilforooshan and Edriss, 2004; Ducrocq, 2005; Bach, 2011), although some studies found no effect of AFC on culling up to $310 \mathrm{~d}$ from calving (Ettema and Santos, 2004) and survival up to the second calving (Simerl et al., 1992).

\section{Heritability Estimates}

Heritability estimates among S1 to S3 were in good agreement with results from an earlier study in a similar, partly overlapping, data set (Heise et al., 2016).

The range of heritability estimates for AFI from literature is large: 0.24 in Dutch Friesians (Jansen et al., 1987), 0.22 in Ayrshire and Friesian cows (Mäntysaari et al., 2002), 0.12 in Canadian Holsteins (Raheja et al., 1989), 0.10 to 0.64 for Holstein cows in different herds in Germany (Bergk, 2011), and 0.13 in Canadian Holstein heifers (Jamrozik et al., 2005). For beef cattle, heritability estimates for age at puberty range from 0.10 to 0.67 (as reviewed by Cammack et al., 2009). Our heritability estimate (0.24) for AFI lies well in the previously reported range but is relatively high compared with most other functional traits. A reason might be that farmers focus mainly on BW when determining the optimum point for the first insemination, as proposed by, for example, Archbold et al. (2012), because BW is a better indicator for the onset of puberty than age (as reviewed by Sejrsen and Purup, 1997), and heritability estimates for BW at different times during the rearing period were reported to be high, ranging from 0.41 to 0.83 (Groen and Vos, 1995; Coffey et al., 2006).

The mean heritability estimate for FLI (0.007) was somewhat lower than estimated in a previous study on German Holstein heifers (Liu et al., 2008) and at the lower end of estimates for similar traits reported in other studies (Hansen et al., 1983; Berry et al., 2003). A wide range of heritability estimates was also reported for AFC, ranging from 0.02 (VanRaden and Klaaskate, 1993) to 0.47 (Ruiz-Sánchez et al., 2007). Our value (0.10) lies toward the lower bound of this range and

Table 4. Mean estimated genetic parameters from 5 samples between survival traits S1 to S3, age at first insemination (AFI), interval from first to last insemination (FLI), and age at first calving (AFC) ${ }^{1}$

\begin{tabular}{lcccccc}
\hline Trait $^{2}$ & $\mathrm{~S} 1$ & $\mathrm{~S} 2$ & $\mathrm{~S} 3$ & $\mathrm{AFI}$ & FLI & AFC \\
\hline S1 & $\mathbf{0 . 0 2 3}$ & 0.86 & 0.48 & -0.08 & -0.14 & -0.09 \\
& $(0.002)$ & $(0.08)$ & $(0.06)$ & $(0.15)$ & $(0.10)$ & $(0.12)$ \\
S2 & $\mathrm{ND}^{3}$ & $\mathbf{0 . 0 1 6}$ & 0.58 & -0.02 & -0.20 & -0.06 \\
& & $(0.004)$ & $(0.11)$ & $(0.07)$ & $(0.06)$ & $(0.09)$ \\
S3 & $\mathrm{ND}$ & $\mathrm{ND}$ & $\mathbf{0 . 0 2 8}$ & -0.10 & -0.44 & -0.20 \\
& & & $(0.003)$ & $(0.09)$ & $(0.17)$ & $(0.12)$ \\
AFI & -0.02 & -0.03 & -0.02 & $\mathbf{0 . 2 3 9}$ & 0.12 & $\mathrm{NE}^{4}$ \\
& $(0.01)$ & $(0.00)$ & $(0.01)$ & $(0.069)$ & $(0.18)$ & $\mathrm{NE}$ \\
FLI & -0.02 & -0.02 & -0.03 & -0.02 & $\mathbf{0 . 0 0 7}$ & $(0.002)$ \\
\multirow{2}{*}{ AFC } & $(0.01)$ & $(0.00)$ & $(0.00)$ & $(0.00)$ & $\mathrm{NE}$ & $\mathbf{0 . 1 0 3}$ \\
& -0.03 & -0.03 & -0.04 & $\mathrm{NE}$ & & $(0.025)$ \\
\hline
\end{tabular}

${ }^{1}$ Heritability estimates on diagonal (in bold), genetic correlations above and residual correlations below diagonal (SD in parentheses).

${ }^{2} \mathrm{~S} 1$ to $\mathrm{S} 3=$ survival of the periods 0 to $49 \mathrm{~d}, 50$ to $249 \mathrm{~d}$, and $250 \mathrm{~d}$ to the second calving, respectively.

${ }^{3}$ Not defined, because all individuals that had observations for S2 or S3 were coded 1 for all previous survival traits.

${ }^{4}$ Not estimated. 
well below the heritability estimate for AFI (0.24). This is also in accordance with findings of Mäntysaari et al. (2002), who reported heritability estimates of 0.22 for age at breeding and 0.05 for age at first calving.

\section{Genetic Correlations}

Mean genetic correlations of AFI with S2 were zero and with S1 and S3 were slightly negative, but estimates varied substantially between the different samples. For example, the estimates for the genetic correlation between AFI and S1 ranged from -0.29 to 0.04 across the 5 samples. The slightly negative correlations were in agreement with the phenotypic results from our study. This suggests that heifers with a higher genetic potential for early breeding also have a slightly higher genetic potential for survival of the first lactation. Genetic correlations between FLI and the different survival traits showed a clear pattern, with smaller negative correlations to S1 and S2 and a much stronger negative correlation to S3. As for the discussed phenotypic patterns, this might result from the implied influence of reproductive performance on S3. This result must be taken cautiously due to the extremely low heritability estimate for FLI (0.007), which was close to the lower bound of the parameter space. However, this pattern was consistent over all samples and repeated in a weaker form for the genetic correlations between $\mathrm{AFC}$ and the respective survival traits, which might result from the fact that FLI is a component of AFC. The close to zero estimate for the genetic correlation between AFI and FLI is in accordance with other studies on similar traits (Raheja et al., 1989; Jamrozik et al., 2005).

In our study, we concentrated on the definition of AFC as a heifer development and fertility trait and its relationship to survival traits. Previous studies have shown that AFC affects milk yield as well (e.g., Moore et al., 1991). Therefore, the interrelationship between milk yield, AFC, and survival needs to be investigated further, especially when considering models for functional longevity, which means the inclusion of an effect for milk yield relative to the herd mean to correct for voluntary culling (e.g., Ducrocq et al., 1988).

\section{Comparison of Models With and Without Correction for AFC}

To further evaluate the effect of the correction for AFC in the sample data sets used for our study, we also estimated variance components for $\mathrm{S} 1, \mathrm{~S} 2$, and $\mathrm{S} 3$, including a first-order regression on AFC. The estimated variance components were very similar to those without the correction, indicating that the effect of AFC explains only a minor proportion of the variability of survival. Furthermore, we compared EBV for the respective survival traits of the first lactation from the prototype version of the new genetic evaluation system for longevity between scenarios with and without correction for AFC, where AFC was considered as a class variable with levels changing weekly. Additionally, a herd $\times$ year $\times$ season effect and a fixed effect for the region (federal states) were included. Genetic parameters were similar to those in Heise et al. (2016). Correlations between EBV for bulls born later than 1995 and having at least 50 daughters in the data set $(\mathrm{n}=19,972)$ were 0.99 (S1), 0.99 (S2), and 0.98 (S3), indicating some re-ranking of bulls between the 2 scenarios. When comparing the top 20 bulls for S3 between both scenarios, only 11 bulls were in common, illustrating massive reranking of the top lists.

\section{Implications}

The aim of genetic evaluations for longevity is to assess the genetic potential of animals to resist culling, either involuntary culling only, which is referred to as functional longevity (Ducrocq et al., 1988) or involuntary and voluntary culling at the same time (van Pelt et al., 2015). Both approaches include the genetic variance of longevity contributed by functional traits. Our results indicate that AFC has low, but potentially nonzero, genetic correlations to survival. Accordingly, correcting for AFC in models for genetic evaluations of survival or longevity might remove functional genetic variance from survival traits. Two other approaches could be examined to avoid this issue while still using information on AFC and its underlying traits in genetic evaluations for functional longevity: first, underlying traits of AFC could be considered as genetically correlated traits in multivariate approaches to increase the reliability of breeding values for survival. Second, AFC could be corrected for its genetic component and then used as a covariate or fixed effect in survival models, if a correction for the environmental or management part of this effect is deemed necessary.

\section{CONCLUSIONS}

Based on the parameters estimated in this study, correcting for $\mathrm{AFC}$ in models for genetic evaluations of survival or longevity is expected to remove functional genetic variance from survival traits and should thus be reconsidered because it might remove a part of the genetic determination of the target trait. 


\section{ACKNOWLEDGMENTS}

The German national FBF (Förderverein Bioökonomieforschung e.V., "Association for Bioeconomy Research," Bonn, Germany) is thanked for the financial support.

\section{REFERENCES}

Allaire, F. R., and J. P. Gibson. 1992. Genetic value of herd life adjusted for milk production. J. Dairy Sci. 75:1349-1356. https://doi .org/10.3168/jds.S0022-0302(92)77886-2.

Archbold, H., L. Shalloo, E. Kennedy, K. M. Pierce, and F. Buckley. 2012. Influence of age, body weight and body condition score before mating start date on the pubertal rate of maiden HolsteinFriesian heifers and implications for subsequent cow performance and profitability. Animal 6:1143-1151. https://doi.org/10.1017/ S1751731111002692.

Bach, A. 2011. Associations between several aspects of heifer development and dairy cow survivability to second lactation. J. Dairy Sci. 94:1052-1057. https://doi.org/10.3168/jds.2010-3633.

Bergk, N. 2011. Genetisch-statistische Untersuchungen zum Wachstum weiblicher Jungrinder der Rasse Holstein auf Basis von zum Zeitpunkt der ersten Besamung erhobenen Gewichten. MartinLuther-Universität, Halle-Wittenberg, Germany.

Berry, D. P., F. Buckley, P. Dillon, R. D. Evans, M. Rath, and R. F. Veerkamp. 2003. Genetic relationships among body condition score, body weight, milk yield, and fertility in dairy cows. J. Dairy Sci. 86:2193-2204. https://doi.org/10.3168/jds.S0022 -0302(03)73809-0.

Boettcher, P. J., L. K. Jairath, and J. C. M. Dekkers. 1999. Comparison of methods for genetic evaluation of sires for survival of their daughters in the first three lactations. J. Dairy Sci. 82:1034-1044. https://doi.org/10.3168/jds.S0022-0302(99)75324-5.

Cammack, K. M., M. G. Thomas, and R. M. Enns. 2009. Review: Reproductive traits and their heritabilities in beef cattle. Prof. Anim. Sci. 25:517-528.

Campos, M. S., C. J. Wilcox, C. M. Becerril, and A. Diz. 1994. Genetic parameters for yield and reproductive traits of Holstein and Jersey cattle in Florida. J. Dairy Sci. 77:867-873. https://doi.org/ 10.3168/jds.S0022-0302(94)77021-1.

Coffey, M. P., J. Hickey, and S. Brotherstone. 2006. Genetic aspects of growth of Holstein-Friesian dairy cows from birth to maturity. J. Dairy Sci. 89:322-329. https://doi.org/10.3168/jds.S0022 $-0302(06) 72097-5$.

Dematawewa, C. M. B., and P. J. Berger. 1998. Genetic and phenotypic parameters for 305-day yield, fertility, and survival in Holsteins. J. Dairy Sci. 81:2700-2709. https://doi.org/10.3168/jds .S0022-0302(98)75827-8.

Dempster, E. R., and I. M. Lerner. 1950. Heritability of threshold characters. Genetics 35:212-236.

Destatis. 2013. Forst, Landwirtschaft Und Fischerei Viehbestand. Accessed Dec. 16, 2016. https://www.destatis .de/DE/Publikationen/Thematisch/LandForstwirtschaft/ ViehbestandTierischeErzeugung/Viehbestand2030410135314.pdf ?__blob=publicationFile.

Ducrocq, V. 2005. An improved model for the French genetic evaluation of dairy bulls on length of productive life of their daughters. Anim. Sci. 80:249-256. https://doi.org/10.1079/ASC41720249.

Ducrocq, V., R. L. Quaas, E. J. Pollak, and G. Casella. 1988. Length of productive life of dairy cows. 1. Justification of a Weibull model. J. Dairy Sci. 71:3061-3070. https://doi.org/10.3168/jds.S0022 -0302(88)79906-3.

Ettema, J. F., and J. E. P. Santos. 2004. Impact of age at calving on lactation, reproduction, health, and income in first-parity Holsteins on commercial farms. J. Dairy Sci. 87:2730-2742. https:// doi.org/10.3168/jds.S0022-0302(04)73400-1.
Gianola, D. 1982. Theory and analysis of threshold characters. J. Anim. Sci. 54:1079-1096. https://doi.org/10.2134/jas1982.5451079x.

Gill, G. S., and F. R. Allaire. 1976. Relationship of age at first calving, days open, days dry, and herdlife to a profit function for dairy cattle. J. Dairy Sci. 59:1131-1139. https://doi.org/10.3168/jds .S0022-0302(76) 84333-0.

Groen, A. F., and H. Vos. 1995. Genetic parameters for body weight and growth in Dutch Black and White replacement stock. Livest. Prod. Sci. 41:201-206. https://doi.org/10.1016/0301-6226(94)00062-C.

Groeneveld, E., M. Kovac, and N. Mielenz. 2010. VCE User's Guide and Reference Manual Version 6.0. Institute of Farm Animal Genetics, Friedrich Loeffler Institute (FLI), Neustadt, Germany.

Haile-Mariam, M., P. J. Bowman, and M. E. Goddard. 2003. Genetic and environmental relationship among calving interval, survival, persistency of milk yield and somatic cell count in dairy cattle. Livest. Prod. Sci. 80:189-200. https://doi.org/10.1016/S0301 $-6226(02) 00188-4$

Hansen, L. B., A. E. Freeman, and P. J. Berger. 1983. Association of Heifer fertility with cow fertility and yield in dairy cattle. J. Dairy Sci. 66:306-314. https://doi.org/10.3168/jds.S0022-0302(83)81790 $-1$.

Heise, J., Z. Liu, K. F. Stock, S. Rensing, F. Reinhardt, and H. Simianer. 2016. The genetic structure of longevity in dairy cows. J. Dairy Sci. 99:1253-1265. https://doi.org/10.3168/jds.2015-10163.

Holtsmark, M., B. Heringstad, and J. Ødegård. 2009. Predictive abilities of different statistical models for analysis of survival data in dairy cattle. J. Dairy Sci. 92:5730-5738. https://doi.org/10.3168/ jds.2009-2132.

Interbull. 2016. National genetic evaluation forms provided by countries. Accessed Dec. 13, 2016. http://interbull.org/ib/geforms.

Jamrozik, J., J. Fatehi, G. J. Kistemaker, and L. R. Schaeffer. 2005. Estimates of genetic parameters for Canadian Holstein female reproduction traits. J. Dairy Sci. 88:2199-2208. https://doi.org/10 .3168/jds.S0022-0302(05)72895-2.

Jansen, J., J. van der Werf, and W. de Boer. 1987. Genetic relationships between fertility traits for dairy cows in different parities. Livest. Prod. Sci. 17:337-349. https://doi.org/10.1016/0301 $-6226(87) 90081-9$.

Kaplan, E. L., and P. Meier. 1958. Nonparametric estimation from incomplete observations. J. Am. Stat. Assoc. 53:457-481. https:// doi.org/10.1080/01621459.1958.10501452.

Liu, Z., J. Jaitner, F. Reinhardt, E. Pasman, S. Rensing, and R. Reents. 2008. Genetic evaluation of fertility traits of dairy cattle using a multiple-trait animal model. J. Dairy Sci. 91:4333-4343. https://doi.org/10.3168/jds.2008-1029.

Mäntysaari, P., M. Ojala, and E. A. Mäntysaari. 2002. Measures of before and after breeding daily gains of dairy replacement heifers and their relationship with first lactation milk production traits. Livest. Prod. Sci. 75:313-322. https://doi.org/10.1016/S0301 -6226(01)00329-3.

Miglior, F., B. L. Muir, and B. J. Van Doormaal. 2005. Selection indices in Holstein cattle of various countries. J. Dairy Sci. 88:12551263. https://doi.org/10.3168/jds.S0022-0302(05)72792-2.

Moore, R. K., B. W. Kennedy, L. R. Schaeffer, and J. E. Moxley. 1991. Relationships between age and body weight at calving and production in first lactation Ayrshires and Holsteins. J. Dairy Sci. 74:269-278. https://doi.org/-0302(91)78170-8.

Nilforooshan, M. A., and M. A. Edriss. 2004. Effect of age at first calving on some productive and longevity traits in Iranian Holsteins of the Isfahan province. J. Dairy Sci. 87:2130-2135. https://doi.org/ 10.3168/jds.S0022-0302(04)70032-6.

Norman, H. D., J. R. Wright, M. T. Kuhn, S. M. Hubbard, J. B. Cole, and P. M. VanRaden. 2009. Genetic and environmental factors that affect gestation length in dairy cattle. J. Dairy Sci. 92:2259 2269. https://doi.org/10.3168/jds.2007-0982.

Pinedo, P. J., A. De Vries, and D. W. Webb. 2010. Dynamics of culling risk with disposal codes reported by Dairy Herd Improvement dairy herds. J. Dairy Sci. 93:2250-2261. https://doi.org/10.3168/ jds.2009-2572. 
R Core Team. 2016. R: A Language and Environment for Statistical Computing. R Foundation for Statistical Computing, Vienna, Austria.

Raheja, K. L., E. B. Burnside, and L. R. Schaeffer. 1989. Heifer fertility and its relationship with cow fertility and production traits in Holstein dairy cattle. J. Dairy Sci. 72:2665-2669. https://doi.org/ 10.3168/jds.S0022-0302(89)79407-8.

Rajala-Schultz, P. J., and Y. T. Gröhn. 1999. Culling of dairy cows Part III. Effects of diseases, pregnancy status and milk yield on culling in Finnish Ayrshire cows. Prev. Vet. Med. 41:295-309. https://doi.org/10.1016/S0167-5877(99)00047-1.

Ruiz-Sánchez, R., R. W. Blake, H. M. A. Castro-Gámez, F. Sánchez, H. H. Montaldo, and H. Castillo-Juárez. 2007. Short communication: Changes in the association between milk yield and age at first calving in Holstein cows with herd environment level for milk yield. J. Dairy Sci. 90:4830-4834. https://doi.org/10.3168/ jds.2007-0156.

Sasaki, O., M. Aihara, A. Nishiura, H. Takeda, and M. Satoh. 2015. Genetic analysis of the cumulative pseudo-survival rate during lactation of Holstein cattle in Japan by using random regression models. J. Dairy Sci. 98:5781-5795. https://doi.org/10.3168/jds $.2014-9152$.

Sejrsen, K., and S. Purup. 1997. Influence of prepubertal feeding level on milk yield potential of dairy heifers: A review. J. Anim. Sci. 75:828-835. https://doi.org/10.2527/1997.753828x.

Sewalem, A., F. Miglior, G. J. Kistemaker, P. Sullivan, G. Huapaya, and B. J. Van Doormaal. 2007. Short communication: Modification of genetic evaluation of herd life from a three-trait to a fivetrait model in Canadian dairy cattle. J. Dairy Sci. 90:2025-2028. https://doi.org/10.3168/jds.2006-719.
Simerl, N. A., C. J. Wilcox, and W. W. Thatcher. 1992. Postpartum performance of dairy heifers freshening at young ages. J. Dairy Sci 75:590-595. https://doi.org/10.3168/jds.S0022-0302(92)77796-0.

Therneau, E. 2016. A Package for Survival Analysis in S. Version 2.40. Accessed Nov. 1, 2016. https://CRAN.R-project.org/package =survival.

van Pelt, M. L., T. H. E. Meuwissen, G. de Jong, and R. F. Veerkamp. 2015. Genetic analysis of longevity in Dutch dairy cattle using random regression. J. Dairy Sci. 98:4117-4130. https://doi.org/10 $.3168 /$ jds.2014-9090.

VanRaden, P. M., and E. J. H. Klaaskate. 1993. Genetic evaluation of length of productive life including predicted longevity of live cows. J. Dairy Sci. 76:2758-2764. https://doi.org/10.3168/jds.S0022 $-0302(93) 77613-4$.

Vinson, W. E., J. M. White, and R. H. Kliewer. 1976. Overall classification as a selection criterion for improving categorically scored components of type in Holsteins. J. Dairy Sci. 59:2104-2114. https://doi.org/10.3168/jds.S0022-0302(76)84494-3.

Visscher, P. M., and M. E. Goddard. 1995. Genetic parameters for milk yield, survival, workability, and type traits for Australian dairy cattle. J. Dairy Sci. 78:205-220. https://doi.org/10.3168/jds .S0022-0302(95)76630-9.

VIT. 2016. Estimation of breeding values for milk production traits, somatic cell score, conformation, productive life and reproduction traits in German dairy cattle. Accessed Dec. 13, 2016. http://www.vit.de/fileadmin/user_upload/vit-fuers-rind/ zuchtwertschaetzung/milchrinder-zws-online/Zws_Bes_eng.pdf. 